\title{
La participación de las mujeres en el escenario político, y su reafirmación a través de las acciones afirmativas propuestas en el acuerdo final de paz*
}

The participation of women in the political scenario, and their reaffirmation through the affirmative actions proposed in the final peace agreement

María Alejandra López Agudelo

Fecha correspondencia:

Recibido: 14 de octubre de 2021. Revisión: 20 de mayo de 2021. Aceptado: 28 de mayo de 2021.

\section{Forma de citar:}

López, María Alejandra. (2021)

"La participación de las mujeres

en el escenario político, y su

reafirmación a través de las

acciones afirmativas propuestas en

el acuerdo final de paz." En: Revista

CES Derecho. Vol. 12, No. 1, enero a junio de 2021, 154-166.

\section{Open access}

Términos de uso

Licencia creative commons

Etica de publicaciones

Revisión por pares

Gestión por Open Journal System

DOl: https://dx.doi.org/10.21615/

cesder.12.1.8

ISSN: $2145-7719$

Sobre el artículo:

* Este artículo es resultado de

la investigación titulada "La

participación de la Mujer en

el escenario Político desde el enfoque de equidad de género. El caso de Estamos Listas Medellín, 2019", realizada en el marco de la convocatoria para proyectos de

\section{Resumen}

El presente artículo pretende abordar el surgimiento de las acciones afirmativas como mecanismos o instrumentos equiparadores de derechos políticos para grupos excluidos, como lo son las mujeres en general, desde lo consagrado en el Acuerdo Final de Paz firmado entre el Gobierno Nacional y las FARC- EP en el año 2016. El foco central del escrito será el Punto Dos: "Participación política: Apertura democrática para construir la paz, y las medidas o acciones afirmativas", es decir, lo atinente a los espacios de representación y participación política activa en los escenarios de poder y toma de decisiones, del cual se pretende la identificación de las acciones afirmativas, así como verificación de la implementación de estas en el país.

Palabras clave: Acuerdo Final de Paz, acción afirmativa, mujeres, participación política, poder.

\section{Abstract}

This article addresses the emergence of affirmative actions as mechanisms or instruments to equalize political rights for excluded groups, such as women in general. It will be studied and analyzed from everything about Final Peace Agreement signed between the Colombia's National Government and the FARC-EP in 2016. The central focus of the article will be the second point of the agreement: "Political participation: Democratic opening to build peace, and affirmative measures or actions", that is, everything about representation spaces, active political participation in the power and decision-making, which are the objetive to identify in this article, following always the affirmative actions, as well as verification of their implementation in Colombia.

Keywords: Final Peace Agreement, affirmative actions, women, political participation, authority. 
investigación presentada por estudiantes de pregrado de la Facultad de Derecho y Ciencias Políticas de la Universidad de Antioquia 2019-1, financiada por el Comité de Desarrollo de la Investigación y la Facultad de Derecho y Ciencias Políticas, además de las reflexiones hechas en el curso de profundización de derecho laboral 3. La asesora de este trabajo fue la abogada, docente e investigadora Elvigia Cardona Zuleta. El actual escrito se presenta como articulo corto.

\section{Sobre los autores:}

1. Estudiante del pregrado de derecho de la Universidad de Antioquia.

\section{Introducción}

La participación política, implica la intervención de las personas mediante diversos sistemas, que van en consonancia con la toma de decisiones en órganos o instituciones de poder dentro de un país, y que constituyen, en su gran mayoría, los derechos políticos, como lo predica la Constitución Política de Colombia en su artículo 40 "Todo ciudadano tiene derecho a participar en la conformación, ejercicio y control del poder político". A pesar de dicho mandato constitucional la participación política, tradicionalmente, se ha concedido a los hombres, y destinando a las mujeres a las labores de lo domestico y lo privado, es decir, labores de limpieza y cuidado del hogar. Esto delimitado por los roles sexo-género que se han construido culturalmente.

Las líneas anteriores se pueden constatar con lo que la historia ha develado, es decir, las mujeres en nuestro país pudieron ejercer su derecho al voto a partir de 1957 en los comicios del plebiscito que consultaba el surgimiento del Frente Nacional; asunto demasiado tardío, ya que en el Viejo Continente la gesta de estos derechos se dieron a partir del siglo XIV con Elizabeth Cady Stanton y Lucretia Mott, precursoras de la Declaración de Seneca Falls, documento que visibilizaba las limitaciones que tenían las mujeres y la insuficiencia de derechos, así como el pedido de la reivindicación de estos (González, 2017).

La poca participación femenina en Colombia ha sido tratada desde diversos enfoques, uno de ellos es el normativo, el cual desde la Constitución Política de 1991 introduce un mandato por la igualdad real y material, sin embargo, en términos de participación política, sólo hasta el año 2000 se expide la Ley Estatutaria 581¹', en la que se señala que el $30 \%$ de los altos cargos públicos sean ejercidos por mujeres en los niveles de decisión de las diferentes ramas del poder público, cuestión que posteriormente es reafirmada mediante la Ley Estatutaria 1475 de $2011^{2}$, la cual además, señala entre sus principios la Equidad y la igualdad de género ${ }^{3}$.

Aunado a lo anterior, dicha participación política, actualmente hace parte de la agenda de implementación del Acuerdo Final de Paz (en adelante Acuerdo Final), firmado entre el Gobierno Nacional y Las Fuerzas Armadas Revolucionarias de Colombia - Ejército del Pueblo FARC-EP (en adelante FARC), esto gracias a que en este se reconoce, que pese a la normatividad existente las mujeres siguen siendo objeto de discriminación y exclusión en la esfera de lo público y lo político, y por tanto, se requiere de acciones afirmativas, para alcanzar una real participación en los espacios de representación política y cargos directivos:

Tomando en consideración que las mujeres enfrentan mayores barreras sociales e institucionales para el ejercicio de la participación política como consecuencia de profundas discriminaciones y desigualdades, así como de condiciones estructurales de exclusión y subordinación, lo que genera mayores retos para garantizar su derecho a la participación, enfrentar y transformar estas condiciones históricas implica desarrollar medidas afirmativas que garanticen la participación de las mujeres en los diferentes espacios de representación política y social. Para esto es necesario que se reconozca la situación y condición de las mujeres en sus contextos y particularidades. (Acuerdo Final, 2016, p. 35).

1. Por la cual se reglamenta la adecuada y efectiva participación de la mujer en los niveles decisorios de las diferentes ramas y órganos del poder público de conformidad con los artículos 13, 40 y 43 de la Constitución Nacional y se dictan otras disposiciones.

2. Por la cual se adoptan reglas de organización y funcionamiento de los partidos y movimientos políticos, de los procesos electorales y se dictan otras disposiciones.

3. Equidad e igualdad de género. En virtud del principio de equidad e igualdad de género, los hombres, las mujeres y las demás opciones sexuales gozarán de igualdad real de derechos y oportunidades para participar en las actividades políticas, dirigir las organizaciones partidistas, acceder a los debates electorales y obtener representación política. (Ley 1475 de 2015, art. 1) 
Es decir, los Acuerdos de Paz reconocen como barreras la discriminación y la subordinación de las mujeres para la participación en el escenario político, y con esto cobra importancia la identificación e implementación de ciertas medidas afirmativas para mitigar, y en un posible momento superar esas dificultades sociales y estructurales.

El presente artículo es resultado de la investigación "La participación de la Mujer en el escenario Político desde el enfoque de equidad de género. El caso de Estamos Listas Medellín, 2019", que tenía como objetivo principal comprender esa participación de las mujeres en los escenarios de poder, pero teniendo como foco central lo propuesto desde el Acuerdo Final de Paz, y las medidas afirmativas que de este surgen, para superar la latente precaria participacion femenina en los diferentes niveles del poder público.

\section{Negociación y Acuerdos de Paz entre el Gobierno y FARC-EP}

El Acuerdo Final de Paz entre el Gobierno colombiano y las FARC, surgen de los diálogos realizados entre estos dos actores a partir del año 2012, en la Habana, Cuba, principalmente; pero se podría afirmar que estas negociaciones tuvieron cimientos años atrás en otros gobiernos; desde la administración de Cesar Gaviria Trujillo (1990-1994), se vieron vestigios de diálogos, los cuales tuvieron un fracaso repentino, generando consigo una escalada del conflicto armado en el país; posteriormente, y bajo presiones ciudadanas, el presidente Andrés Pastrana (1998-2002), inicia lo que se conoció como los diálogos de paz del Caguán, en el cual se lograron acuerdos parciales, además de un relevante apoyo del pueblo colombiano y de la comunidad internacional, a pesar de esto dichos diálogos también fracasaron. Después de todo lo anterior, Colombia, en cabeza presidencial de Álvaro Uribe Vélez, generó durante casi una década una política militar, en la cual se pretendía acabar con dicha guerrilla en una ofensiva armada, con esto aumentando el conflicto bélico que sufría el país, y causando una tragedia humanitaria mayor ${ }^{4}$.

En el año 2010, inicia un nuevo gobierno con el Presidente Juan Manuel Santos, el cual empieza a promover diferentes formas de llegar a la paz en el territorio colombiano, contrariando lo que había propuesto el anterior gobierno, es decir, dejar el ataque militar contra las FARC, y proponer una salida dialogada del hostigamiento. A partir de ese momento, y a pesar del poco apoyo ciudadano, se inició públicamente en el año 2012 las conversaciones, las cuales se prolongaron hasta el 2016, anualidad en la cual se firma, como ya se dijo, el Acuerdo Final de Paz entre el Gobierno y las FARC, que se convirtieron en un conjunto de medidas en materia agraria, de participación política y social, superación de economías ilegales, derechos de las víctimas, compromisos para finalizar las hostilidades e implementar mecanismos de verificación, que observa la terminación de conflicto y las beligerancias en el territorio nacional por parte de dicho grupo alzado en armas.

Como se dijo anteriormente, dicho Acuerdo Final fijó unos ejes temáticos a tratar, que los consolidó en puntos específicos en el del texto acordado, fueron en total seis puntos que se distribuyeron así [a manera de breviario corto]:

1. Reforma rural integral: se enmarca en una de las más grandes problemáticas que tiene nuestro país, el acceso y la tenencia de la tierra, teniendo como objetivo generar transformaciones estructurales del campo colombiano, e iniciar el cierre de brechas en este sector, creando un Fondo de Tierras de distribución, el

4. Para más información consultar en: https://pares.com.co/2019/01/04/procesos-de-paz-en-colombia/ 
cual pretende, de manera gratuita, garantizar la tierra a los campesinos que no la tienen o que es insuficiente, además de generar una formalización masiva de predios campesinos, teniendo como mira principal el aumento en la calidad de vida, el buen vivir y la seguridad alimentaria de la población rural.

2. Participación política: Apertura democrática para construir la paz: este punto pretende la apertura de la democracia hacia nuevos participantes, es decir, que los escenarios de poder y toma de decisiones no sigan cooptados por un sector exclusivo de la población, sino que sea un espacio plural, que representen a todas las visiones y posturas que provienen de esa multiplicidad, consignada desde el artículo 1 de la Constitución Política de 1991.

3. Cese al Fuego y de Hostilidades Bilateral y Definitivo y la Dejación de las Armas: se pretende con este punto que se terminen los enfrentamientos armados y hostilidades entre el grupo armada FARC y la Fuerza Pública, uno de sus principales mecanismo para este fin es la dejación y entrega de armamento por parte de las FARC, en este punto hay especial participación de organismos internacionales, como es la Organización de Naciones Unidas (ONU). Además de tratar toda la cuestión desmovilización, reinserción y reincorporación efectiva, de los miembros de este grupo, a la vida social, económica y política.

4. Solución al Problema de las Drogas Ilícitas: este punto, como su nombre lo indica, pretende erradicar el problema de las drogas ilícitas en el país, teniendo como mecanismo principal el abandono por parte de la FARC del cultivo, producción y comercialización de dichas drogas, por tanto medidas como la erradicación y sustitución de cultivos ilícitos y la implementación de programas donde se generen alternativas de producción a los campesinos inmersos en al siembre, son primordiales para superar dicho problema; así como la promoción de un tratamiento diferenciado a los consumidores de dichas sustancias, en el marco y prevalencia de la salud pública y de los derechos humanos.

5. Víctimas: tiene como objetivo primordial la realización del Sistema Integral de Verdad, Justicia, Reparación y Garantías de No Repetición, conjunto de mecanismos tanto judiciales como extrajudiciales para resarcir el daño causado, determinar lo sucedido en la realidad, y reafirmar la voluntad de las FARC de no volver a las armas, pero siempre en procura de la protección a las víctimas del conflicto.

6. Mecanismos de implementación y verificación: dichos mecanismos se fijan con el objetivo de que se dé pleno cumplimiento al Acuerdo Final, creando la Comisión de Seguimiento, Impulso y Verificación a la Implementación del Acuerdo Final, además integrando a la comunidad internacional como veedora y garante de todo el proceso que se adelantará por los actores firmantes.

El Acuerdo Final se construye partiendo del enfoque territorial, diferencial y de género, el cual "supone reconocer y tener en cuenta las necesidades, características y particularidades económicas, culturales y sociales de los territorios y las comunidades, garantizando la sostenibilidad socio-ambiental; y procurar implementar las diferentes medidas de manera integral y coordinada, con la participación activa de la ciudadanía" (Acuerdo Final, 2016, p. 6), es decir, se adoptarán e implementarán acciones afirmativas en favor de grupos que se han determinado como marginados, 
procurando la superación y supresión de las condiciones de desigual y discriminación latentes en dicha población. Esto sin olvidar lo sucedido con las presiones generadas por una fracción de la población colombiana, los cuales se negaban y satanizaban la idea que el Acuerdo Final hiciera referencia directa al enfoque de género, afirmando que se producirían afectaciones a los valores tradicionales adoptados por los colombianos, y por tanto alteraría el núcleo fundamental de la sociedad "La Familia".

El presente artículo se dedicará en adelante al estudio específico del punto dos del Acuerdo Final y las medidas afirmativas que este contiene, además de verificar su implementación, y la aplicación del enfoque de género que se pregona tener.

\section{Punto dos: Participación política: Apertura democrática para construir la paz, y las medidas 0 acciones afirmativas}

Este acápite del Acuerdo Final, como ya se dijo en líneas anteriores, pretende la apertura de la democracia, es decir, que en el escenario político converjan variedad de pensamientos, opiniones y actores, trascendiendo de un espacio excluyente y selectivo en su composición, a uno pluralista, generando una representatividad y mayor filiación en la población colombiana. Lo que trae consigo una ampliación en la participación, y por tanto una toma de decisiones consciente en el ámbito electoral principalmente.

El enfoque territorial, diferencial y de género, que transversaliza el Acuerdo Final, y por tal este punto, aspira principalmente abarcar e incentivar la participación de aquellos sectores a que les ha negado el escenario político, por tanto, las mujeres como grupo poblacional, que ha sido desprovisto de intervenir en la esfera de poder, es foco central, y a las cuales se les pretende blindar de herramientas para su participación, de acuerdo a esto se afirma que:

El Gobierno Nacional y las FARC-EP rechazan cualquier forma de discriminación contra la mujer y reafirman que el aporte de las mujeres como sujetos políticos en la vida pública es vital para el fortalecimiento de la democracia y para el mantenimiento y el fomento de la paz. En la implementación de todo lo acordado en el punto 2 del presente Acuerdo se garantizará el enfoque de género, y se diseñarán y adoptarán las medidas afirmativas necesarias para fortalecer la participación y liderazgo de la mujer y en general para promover el cumplimiento de los anteriores propósitos. (Acuerdo Final, 2016, p. 55).

Además "para fortalecer la participación ciudadana de las mujeres es necesario valorar sus agendas sociales y reconocer su aporte como sujetos políticos en la vida pública, en especial cuando se trata de la promoción y defensa de sus derechos" (Acuerdo Final, 2016, p. 36). De acuerdo a lo anterior, se reconoce el papel trascendental que han tenido las mujeres en la solución de conflictos y en la consolidación de una paz estable y duradera, además de evidenciar la necesidad e importancia de crear e implementar medidas que sirvan a estas para aminorar los efectos perjudiciales que provienen de las prácticas sociales que las tienen inmersas en desigualdades y discriminaciones. 


\section{Pero ¿qué se entiende por medida o acción afirmativa?}

Las medidas o acciones afirmativas han sido conceptualizadas desde distintas esferas, y por distintos autores, pero solo se pueden entender en el contexto de la discriminación, la cual al estar cimentada en estereotipos socialmente construidos, determinan relaciones desiguales, y en muchos casos, de poder injustificadas, en el sentido de que un sector de la población disfruta derechos que a otros le son negados. Perpetuando situaciones, que a hoy se consideran naturales y normales, pero que haciéndoles un análisis mínimo se pueden determinar cómo limitadoras.

Para superar y deconstruir dichas relaciones de desigualdad estructural y formar relaciones basadas en el reconocimiento del otro como par, y de la realización de sus derechos, será necesario crear y aplicar medidas o acciones afirmativas, que se definen como:

Aquellas acciones que reducen o eliminan prácticas discriminatorias contra sectores excluidos de la población tales como mujeres, o grupos étnicos o de cierta preferencia sexual. Se busca con ello darles un trato preferencial y utilizar mecanismos diseñados expresamente para obtener resultados. (Begné, 2012, p. 1).

Según Thomas Sowell históricamente este concepto se empezó a usar en el ámbito Norteamericano haciendo referencia a affirmative action, en el entendido de discriminación positiva (Durango, 2016), pero es en el Viejo Continente que se da la significación de acción afirmativa, a partir del término positive action, el cual suple y trasforma el anterior concepto estadounidense, dándole un contenido de mayor y mejor alcance, teniendo como pretensión:

Cuestionar y modificar aquellas situaciones fácticas que impiden y obstaculizan que los grupos excluidos e individuos alcancen la igualdad efectiva en el reclamo por sus derechos. Con otras palabras, la acción afirmativa restablece la igualdad en la que se encuentran diversos grupos sociales a los que se ha negado o restringido la posibilidad de acceder y participar en la configuración, validación y reclamos de sus derechos en igualdad de oportunidades (Durango, 2016, p.5).

Pero su conceptualización no solo ha sido teórica, estas medidas vienen dadas desde la Constitución Política de 1991, en su artículo 13, donde el constituyente no solo pretendió visibilizar la innegable desigualdad y discriminación en la que se encontraban ciertos grupos poblaciones, sino que decidió remediar y en cierta medida abolir esa situación, predicando que:

Todas las personas nacen libres e iguales ante la ley, recibirán la misma protección y trato de las autoridades y gozarán de los mismos derechos, libertades y oportunidades sin ninguna discriminación por razones de sexo, raza, origen nacional o familiar, lengua, religión, opinión política o filosófica.

El Estado promoverá las condiciones para que la igualdad sea real y efectiva y adoptará medidas en favor de grupos discriminados o marginados.

El Estado protegerá especialmente a aquellas personas que por su condición económica, física o mental, se encuentren en circunstancia de debilidad manifiesta y sancionará los abusos que contra ellas se cometan. 
En ese mismo sentido, pero especificando el grupo poblacional, se dio el mandato del artículo 43, en el cual se reconoció la discriminación recalcitrante e histórica de la que han sido víctimas las mujeres por cuestiones de género, y se predicó su protección especial y diferencial. En relación con esto la Corte Constitucional afirma que:

Las llamadas acciones afirmativas fueron expresamente permitidas en la Carta Constitucional para que el legislador pudiera, sin violar la igualdad, adoptar medidas en favor de ciertas personas o grupos, sin tener que extender el beneficio resultante a otras personas o grupos que, por ello, se consideraran discriminadas. (2005, p. 16) (Negrilla fuera del texto original).

Desde mi percepción, una acción afirmativa es el nombre designado a aquellas medidas transitorias, que se consagran en políticas, o en leyes, destinadas a la protección y el trato diferencial a un grupo de personas, ya sea étnico, social o minoritario, que históricamente ha sufrido el flagelo de la discriminación a causa de injusticias sociales. Tiene como objetivo mitigar dicha discriminación, que se traduce en desigualdad política, económica, cultural y/o social, además de aspira a generar cambios estructurales o de fondo en la sociedad, con el fin de ir superando esa situación, y se llegue a un momento de igualdad real y material, con aumento en la calidad de vida de estos y sin necesidad de implementar acciones de este tipo.

De la anterior definición se puede desprender que para hablar de acción afirmativa es necesaria la congregación de unos determinados elementos, como son:

1. Situaciones de discriminación y/o desigualdad a un grupo determinado o determinable, lo cual se puede entender, en palabras de la Corte Constitucional (1994), como: "[...] conducta, actitud o trato que pretende - consciente o inconscientemente - anular, dominar o ignorar a una persona o grupo de personas, con frecuencia apelando a preconcepciones o prejuicios sociales o personales, y que trae como resultado la violación de sus derechos fundamentales" (p. 20).

2. Configuración del elemento humano, es decir, la existencia de unas personas a las cuales se les afecta con dichas situaciones.

3. Necesidad de adoptar dichas medidas, es decir, que solo se podrá acudir a estas cuando no es posible lograr los objetivos de superación de la posición desfavorable con otro tipo de medidas.

4. Una ley o política que produzca el trato diferencial, con esto manifestándose la legalidad que deberán tener dichas acciones.

5. Transitoriedad de la acción, es decir, que no se perpetúa en el tiempo, sino que se ejercite por un periodo determinado, y poder llegar a esa modificación social y a la superación de las desigualdades. Es decir, "el establecimiento y duración deberá limitarse estrictamente al periodo necesario para lograr la igualación de las condiciones de vida en el sector social afectado" (Rey, 2011, pág. 84).

6. Objetivo de la acción, que será siempre aminorar el efecto nocivo de las prácticas sociales, que han ubicado a esos grupos o personas en posiciones desfavorables. 


\section{Análisis de la implementación de las medidas afirmativas propuestas desde el punto dos del Acuerdo Final}

A partir de la conceptualización anterior se realizará una verificación de la implementación del Acuerdo Final en lo concerniente a las medidas afirmativas del punto dos, pero para efectos de dicha verificación se hace necesario determinar cuántas y cuáles son las acciones establecidas a lo largo del nombrado texto, según los elementos ya estudiados. Se debe aclarar, que a pesar de que el Acuerdo Final este transversalizado por un enfoque territorial, diferencial y de género, no todas sus propuestas van dirigidas a superar o aminorar situaciones adversas de las mujeres, muchas de estas van tendientes a vencer problemas estructurales de la sociedad colombiana en general, que a pesar de cobijar al sector femenino no podrían ser tomadas como medidas o acciones afirmativas, ya que no cumplen el objetivo principal para el cual se crean.

A lo largo de las 22 páginas que comprende dicho punto, se pudo encontrar que 48 veces se habló expresamente de mujer o mujeres, que en 6 ocasiones se hizo alusión al género, y se pudo contabilizar un total de 11 acciones afirmativas, todas ellas tendiente a superar una discriminación y un desfavorecimiento histórico sufrido por las mujeres, las cuales son las siguientes:

1. Con ese objetivo el Gobierno creará un Consejo Nacional para la Reconciliación y la Convivencia, el cual estará integrado por representantes del Gobierno, el Ministerio Público, quienes designen los partidos y movimientos políticos, incluido el que surja del tránsito de las FARC-EP a la actividad política legal, organizaciones y movimientos sociales, en particular de mujeres, campesinos y campesinas, gremios, minorías étnicas, iglesias, confesiones religiosas, organizaciones basadas en la fe y organizaciones del sector religioso, el sector educativo, entre otros. (Acuerdo Final, 2016, p. 47).

2. Promoción de la no estigmatización a grupos en condiciones de vulnerabilidad o discriminados como las mujeres, los pueblos y comunidades étnicas, población LGBTI, los jóvenes, niños y niñas y adultos mayores, las personas en condición de discapacidad, las minorías políticas y las minorías religiosas. (Acuerdo Final, 2016, p. 47).

3. Capacitar a funcionarias y funcionarios públicos y a líderes y lideresas de las organizaciones y movimientos sociales para garantizar la no estigmatización. (Acuerdo Final, 2016, p. 47).

4. Los mecanismos de control y veeduría ciudadana que se prevean contarán con la participación efectiva de las mujeres. (Acuerdo Final, 2016, pág. 48).

5. Fortalecer y promover la construcción de presupuestos participativos sensibles al género y los derechos de las mujeres en el nivel local. (Acuerdo Final, 2016, p. 51).

6. Promover campañas de información, capacitación, pedagogía y divulgación, que estimulen la participación electoral a nivel nacional y regional, con especial énfasis en promover una mayor participación de las mujeres, de poblaciones vulnerables y de territorios especialmente afectados por el conflicto y el abandono. (Acuerdo Final, 2016, p. 52). 
7. Realizar una campaña nacional de cedulación masiva, con prioridad en las zonas marginadas de los centros urbanos y en las zonas rurales, particularmente en las más afectadas por el conflicto y el abandono y previendo medidas para facilitar el acceso a esta campaña por parte de las mujeres rurales. (Acuerdo Final, 2016, pág. 52).

8. Promover un ejercicio ampliamente participativo de diagnóstico con enfoque de género, de los obstáculos que enfrentan estas poblaciones en el ejercicio del derecho al voto, y adoptar las medidas correspondientes. (Acuerdo Final, 2016, p. 51).

9. Promoción de los valores democráticos, de la participación política y de sus mecanismos, para garantizar y fomentar su conocimiento y uso efectivo y así fortalecer el ejercicio de los derechos consagrados constitucionalmente, a través de campañas en medios de comunicación y talleres de capacitación. Se hará especial énfasis en las poblaciones más vulnerables como la población campesina, las mujeres, las minorías religiosas, los pueblos y comunidades étnicas y la población LGBTI. Estas campañas incorporarán en sus contenidos valores que enfrenten las múltiples formas de discriminación. (Acuerdo Final, 2016, p. 55).

10. Programa para la promoción de la participación y liderazgo de la mujer en la política. (Acuerdo Final, 2016, p. 55).

11. Como complemento de lo acordado en el marco de los puntos 2.2 y 2.3 sobre acceso a medios para organizaciones y movimientos sociales y para partidos y movimientos políticos, respectivamente, el Gobierno se compromete a habilitar un canal institucional de televisión cerrada orientado a los partidos y movimientos políticos con personería jurídica, para la divulgación de sus plataformas políticas, en el marco del respeto por las ideas y la diferencia. Ese canal también servirá para la divulgación del trabajo de organizaciones de víctimas, de las organizaciones y movimientos sociales, la promoción de una cultura democrática de paz y reconciliación y de valores no discriminatorios y de respeto al derecho de las mujeres a una vida libre de violencias, así como la divulgación de los avances en la implementación de los planes y programas acordados en el marco de este Acuerdo. (Acuerdo Final, 2016, p. 56).

Además, en este punto se cuenta con un acápite corto, que se tituló "Promoción de la participación política y ciudadana de la mujer en el marco del presente Acuerdo" (p. 55). En el cual se visibiliza que las mujeres han sido objeto de discriminación, subordinación y subrepresentación a través del tiempo, y por tanto se hace necesario:

El fortalecimiento de la participación política y ciudadana de las mujeres en pie de igualdad incluye adoptar medidas que contribuyen a garantizar una representación equilibrada de hombres y mujeres en la conformación de todas las instancias a que se refiere este acuerdo. Así mismo, se requiere propender por la participación equilibrada y el protagonismo de las mujeres al interior de organizaciones y movimientos sociales y partidos políticos. Con el fin de crear conciencia de derechos y promover nuevos liderazgos de las mujeres, se pondrán en marcha programas de formación sobre sus derechos políticos y formas de participación política y ciudadana. (Acuerdo Final, 2016, p. 55). 
Aunado a lo anterior, es de recordar que el Acuerdo Final, tiene veedores y acompañantes internacionales para la implementación, como son por ejemplo el Instituto Kroc, la Organización de Naciones Unidas, y especialmente para el punto dos el Instituto Holandés para la Democracia Multipartidaria (NIMD), en ese sentido estos organismos serán las principales miras para determinar cuál es el estado e implementación del punto dos del Acuerdo Final.

Es así como para el año 2017, es decir, en el primer año de vigencia e implementación del Acuerdo Final, se observa que se tuvo avances frente al tema de políticas y normatividad tendiente a saldar deudas existentes con la población colombiana, como es la aprobación en el Senado de la Ley Estatutaria 03 "por medio del cual se adopta el Estatuto de la Oposición Política y algunos derechos a las agrupaciones políticas independientes", el cual en su artículo 5, literal d, profesa el reconocimiento de principios que han sido reclamados con vehemencia por movimientos feministas como son la paridad, la alternancia y la universalidad de los derechos políticos. (Instituto Kroc, 2017), además de reiterar la necesidad de crear e implementar planes, proyectos y programas con enfoque de género para la protección y seguridad de las personas que participen en política. (Estatuto de Oposición, 2018). Tal Ley fue promulgada el 9 de julio de 2018, por tanto, se podría afirmar que esta fue un logro final de dicha anualidad.

Se expidieron los Decretos N¹54 de 20175, 895 del 29 de mayo de 20176, 2078 de 7 de diciembre 72124 del 18 de diciembre de 20178, y la Directiva N002 de 14 de junio de $2017^{9}$, tendientes a la protección y seguridad de las personas participantes en los escenarios políticos, normativas que tuvieron un aporte insuficiente en cuanto a la aplicación del enfoque de género, ya que "no contemplan desarrollos concretos donde pueda materializarse" (Instituto Kroc, 2017, p. 65).

En relación al año 2018, se creó un Comité de Género al interior de la Unidad Nacional de Protección, además se adoptó mediante Resolución N0845 de 2018 el Programa Integral de Garantías para mujeres lideresas y defensoras de derechos humanos, el cual tiene como fin "garantizar un ambiente seguro para las mujeres que fungen como líderes y defiendes los derechos humanos dentro del territorio colombiano y en su representación" (Ministerio del Interior, 2018, p. 2), iniciando su implementación en Putumayo y Montes de María, donde se encuentran mesas con foros permanentes, las cuales son:

"concebidas como espacios de interlocución entre mujeres organizadas (en organizaciones mixtas y de mujeres), sociedad civil e institucionalidad local/ nacional, que buscan promover las medidas de prevención, protección y garantías de no repetición necesarias para el ejercicio libre y seguro de la labor de liderazgo y defensa de los derechos humanos de las mujeres de estas dos regiones (Red Nacional de Mujeres Defensoras, Tejedoras de Vida del Putumayo y Sisma Mujer, 2019, p. 5).

5. Por el cual se crea la Comisión Nacional de Garantías de Seguridad en el marco del Acuerdo Final, suscrito entre el Gobierno Nacional y las FARC-EP el 24 de noviembre de 2016

6. "Por el cual se crea el Sistema Integral de Seguridad para el Ejercicio de la Política"

7. "Por el cual se adiciona el Capítulo 5, del Título 1, de la Parte 4, del Libro 2 del Decreto 1066 de 2015, Decreto Único Reglamentario del Sector Administrativo del Interior, sobre la ruta de protección colectiva de los derechos a la vida, la libertad, la integridad y la seguridad personal de grupos y comunidades" 8. "Por el cual se reglamenta el sistema de prevención y alerta para la reacción rápida a la presencia, acciones y/o actividades de las organizaciones, hechos y conductas criminales que pongan en riesgo los derechos de la población y la implementación del Acuerdo Final para la Terminación del Conflicto y la Construcción de una Paz Estable y Duradera"

9. Determina los lineamientos para la protección de los derechos de defensoras y defensores de derechos humanos. Reemplazó con ella la directiva 12 de 2010 
A pesar de mencionar este asunto como un avance para la implementación del punto dos del Acuerdo Final, no desconozco que este Programa ha sido un proceso proyectado y elaborado mucho antes de la firma de este, por tanto no es posible dar crédito a tal implementación, ya que se estaría invisibilizando el trabajo y la lucha de mujeres y organizaciones sociales que durante años han aportado para que esto saliera avante.

En esta misma anualidad, se evidenció que la participación de las mujeres, a pesar de lo implementado, no incrementa, además según el Instituto Kroc:

Se presentan dificultades para la adecuada participación de las mujeres a pesar de lo establecido en el artículo 2 del Decreto $\mathbf{N}^{\circ} \mathbf{1 5 4}$ de $\mathbf{2 0 1 7}$ que le dio origen a esta instancia. Sólo una mujer es miembro de pleno derecho, en la

Comisión Nacional De Garantías de Seguridad, y el resto de la participación femenina queda reducida a delegadas o personal técnico. (2018, p. 80) (Negrilla fuera del texto original)

Aunado a esta dificultad, se encuentra la mínima implementación que tuvo el año 2018 en cuanto al punto dos y las medidas afirmativas, los pocos avances sustantivos, la aún ausencia de mecanismos de protección para las mujeres, y la poca participación que tienen estas en los diferentes escenarios de poder y de toma decisiones creados, son el resumen de un año precario en la puesta en marcha del Acuerdo Final.

Por último, está la implementación dada en el tercer año del Acuerdo Final, es decir, año 2019, el cual se reconoce por ser un año violento y turbulento, gracias a los constantes homicidios de lideresas, líderes sociales y excombatientes de las FARC a lo largo y ancho del territorio colombiano, y por haber terminado en un contexto de movilizaciones estudiantiles, sindicales y obreras, reclamando entre muchas cosas la implementación del Acuerdo. Pero aun así, se podría considerar una anualidad de parálisis y estancamiento del desarrollo en las tareas propuestas. Así lo confirma el Instituto Kroc (2019):

A nivel general, este informe advierte sobre los bajos niveles de avance en la implementación de este punto y lo accidentado que ha sido el proceso, por cuanto varias medidas como la reforma política o la creación de las Circunscripciones Especiales Transitorias de Paz no se han aprobado a pesar de que ya han sido presentadas en dos ocasiones al Congreso. En este último caso, preocupa que a pesar de ser un incumplimiento ya que estas circunscripciones hacían parte de las medidas de implementación prioritaria (A.F. 6.1.11) y estaban previstas para que fueran aprobadas finales de 2018, el Gobierno no se haya pronunciado al respecto.

A nivel específico, se observa con preocupación que en el Plan Nacional de Desarrollo que finalmente se aprobó se incluyan limitadamente asuntos clave de este punto y, en varias ocasiones, ignore los que ya se había avanzado en el gobierno que le antecedió. Incluye temas relativos a la protección de defensores de derechos humanos, pero no hay una estrategia ni metas claras para que disminuya la violencia en su contra y mucho menos un reconocimiento de las instancias derivadas del A.F. que ya se encuentran en marcha y tienen precisamente ese propósito. (p.90). 
Por resaltar se encuentra la creación del Sistema Nacional de Mujeres, el cual a través de la transversalización del enfoque de género para las mujeres en distintas entidades estatales, pretende garantizar los derechos humanos de las mujeres, y situar la agenda de estás en el poder público. Aun así, son insuficientes las medidas propuesta por el Gobierno Nacional durante el 2019, convirtiéndose en un año de retroceso y de desarticulación de lo ya implementado, dejando vislumbrar deseos políticos de cambiar el espíritu original del Acuerdo Final, y hasta de un posible hundimiento de éste.

\section{Conclusión}

El Acuerdo Final de Paz, entre otras cosas, reconoce la importancia, el liderazgo y la necesaria participación de las mujeres en los escenarios de poder y toma de decisiones, pero también reconoce la subordinación y la subrepresentación que han tenido a lo largo de la historia colombiana, proponiendo el uso de acciones o medidas afirmativas, con el fin de reconocer, y a la vez superar la discriminación estructural, que se cristaliza en prejuicios y estereotipos, que impiden a las mujeres y niñas el goce efectivo y en condiciones de equidad y justicia sus derechos.

Si bien nuestra Constitución Política de 1991 le dio rango de derecho fundamental a la igualdad, entre hombres y mujeres (art. 13 C.P.), y consignó el deber del Estado de adoptar decisiones tendientes a superar la discriminación del sector femenino en el país, se evidencia que después de 29 años de dicha consigna no se haya superado tan bochornosa situación, y que ello siga teniendo una vasta distancia entre lo normativo y la realidad social. Actualmente, se demuestra de manera constante y en distintos planos, que el anhelo paritario y equitativo está lejos de alcanzarse, y que por el contrario la inequidad parece haberse acentuado y naturalizado con más fervor.

Por otro lado, se concluye que ha quedado rezagada la implementación del Acuerdo Final, evidenciando que muchas de los mandatos que se pretendían allí quedaron en letra muerta. Actualmente hay un anquilosamiento en la realización de los objetivos propuestos desde dicho Acuerdo, con ello suspendiendo y retrasando aquellas acciones tendientes a aminorar las situaciones de discriminación y desigualdad de las que históricamente las mujeres han sido víctimas.

Las acciones estatales frente a la participación política de las mujeres han sido un asunto orientada únicamente a la consolidación cuantitativa, de los cargos, es decir, a través de medidas afirmativas se pretende llegar a un número exacto de curules o puestos ocupados por mujeres, invisibilizando y descuidando la representación real y efectiva, donde los intereses y problemáticas diferenciadas de esta población sean incluidas en las agendas políticas.

\section{Bibliografía}

Begné, P. (2012). Acción afirmativa: una vía para reducir la desigualdad. Ciencia Jurídica, 1(1), 11-16.

Colombia. (1991) Constitución Política de Colombia [Const.]. http://www.presidencia.gov.co

Colombia. (2016). Acuerdo Final para la Terminación del Conflicto y la Construcción de una Paz Estable y Duradera: República de Colombia; FARC-EP. Bogotá, Colombia. http://www.altocomisionadoparalapaz.gov.co/procesos-conversaciones/Documentos\%20compartidos/24-11-2016NuevoAcuerdoFinal.pdf 
Congreso de Colombia. (2011). Ley 1475 de 2011. Diario Oficial n48.130. http://www. secretariasenado.gov.co/senado/basedoc/ley 1475 2011.html

Congreso de Colombia. (2000). Ley 581 de 2000. Diario Oficial n44.026. http://www. secretariasenado.gov.co/senado/basedoc/ley 0581 2000.html

Corte Constitucional (1994, 07 de marzo). Sentencia T-098 de 1994. (Eduardo Cifuentes Muñoz, M.P). https://www.corteconstitucional.gov.co/RELATORIA/1994/T-098-94.htm

Corte Constitucional (2005). Sentencia SU-389 de 2005. (Jaime Araujo Rentería, M.P). https://www.corteconstitucional.gov.co/relatoria/2005/SU389-05.htm

Durango, G. (2016). Las acciones afirmativas como mecanismos reivindicadores de la paridad de género en la participación política inclusiva: Ecuador, Bolivia, Costa Rica y Colombia. Revista de Derecho, (45), 137-168.

González, M. (2017). Breve recorrido por la historia del Feminismo. HistoriAgenda, 3(35), 106-113. http://revistas.unam.mx/index.php/historiagenda/article/view/65416

Instituto Kroc. (2018). Informe de verificación del primer año de implementación del Acuerdo Final de Paz en Colombia para los Verificadores Internacionales Felipe González y José Mujica (A.F. 6.3.2). https://www.verificacion.cerac.org.co/wp-content/uploads/2018/07/Primer-Informe-STCVI-Febrero-2018.pdf

Instituto Kroc. (2018). Segundo informe de verificación de la implementación del Acuerdo Final de Paz en Colombia para los Verificadores Internacionales Felipe González y José Mujica (A.F. 6.3.2). https://www.cinep.org.co/publicaciones/es/producto/segundo-informe-de-verificacion-de-la-implementacion-del-acuerdo-final-de-paz-en-colombia-para-los-verificadores-internacionales-felipe-gonza$\underline{\text { lez-y-jose-mujica-a-f-6-3-2l }}$

Instituto Kroc. (2019). Sexto informe de verificación de la implementación del Acuerdo Final de Paz en Colombia para los Verificadores Internacionales Felipe González y José Mujica (A.F. 6.3.2). https://www.verificacion.cerac.org.co/wp-content/uploads/2019/06/Sexto-informe-trimestral-Secretar\%C3\%ADa-T\%C3\%A9cnica.pdf

Ministerio del Interior. (2018). Resolución N0845 de 2018. http://www.equidadmujer. gov.co/ejes/publicaciones/Resolucion-0845-14-junio-2018.pdf

Red Nacional de Mujeres Defensoras, Tejedoras de Vida del Putumayo y Sisma Mujer. (2019). Relevancia del programa integral de garantías para mujeres lideresas y defensoras de acuerdo con las obligaciones del estado colombiano. https:// www.sismamujer.org/wp-content/uploads/2018/06/RELEVANCIA-DEL-PROGRAMA-INTEGRAL-DE-GARANT\%C3\%8DAS-PARA-MUJERES-LIDERESAS-Y-DEFENSORAS-DE-ACUERDO-CON-LAS-OBLIGACIONES-DEL-ESTADO-COLOMBIA$\underline{\text { NO.pdf }}$

Rey, F. (2011). Marco conceptual de las acciones y discriminaciones positivas. Acciones afirmativas, 65-125. https://www.conapred.org.mx/documentos cedoc/AA MSJ.pdf 